\title{
EXPERIMENTAL STUDY AND NUMERICAL SIMULATION OF THE WATER ENTRY OF A SHIP-LIKE SYMMETRY SECTION WITH AN OBVIOUS BULBOUS BOW
}

\author{
Qiang Wang \\ Pengyao Yu* \\ Boran Zhang \\ Guangzhao Li \\ Dalian Maritime University, China \\ * Corresponding author: yupengyao@dlmu.edu.cn (Pengyao Yu)
}

\begin{abstract}
A bulbous bow is a typical ship structure. Due to the influence of the bulbous bow, complex flow separation and gas capture phenomena may appear during the water entry of ship-like sections. In this paper, experimental and numerical studies on the water entry of a ship-like section with an obvious bulbous bow are carried out. Two thin plates are installed at both ends of the test model to ensure that the flow field during the impact process is approximately twodimensional. The free-fall drop test is carried out in the test rig equipped with guide rails. By changing drop heights, impact pressure on the model surface with different initial impact velocities is measured. A numerical model for simulating the water entry of the ship-like section is established by using the Computational Fluid Dynamics (CFD) method, based on the Navier-Stokes equations. Reasonable time steps and mesh size are determined by convergence analysis. Four different flow models are used in the numerical analysis. It is found that the K-Epsilon turbulence model can present the most reasonable numerical prediction by comparing numerical results with the experimental data. Furthermore, the influence of the bulbous bow on the impact loads is numerically studied by using the validated numerical model. It suggests that the bulbous bow has little effect on the impact force acting on the bow-flared area but, in the position near the bulbous bow, the pressure will be affected by the second slamming and the air cushion.
\end{abstract}

Keywords: Water entry,Bow-flare sections, Slamming,Computational Fluid Dynamics

\section{INTRODUCTION}

The hydrodynamic impact between a ship and a wave can cause severe slamming loads, which threaten the safety of the local and overall structure of the ship's hull [1-3]. In order to better understand the hydrodynamic impact between the ship and the water, water entries of typical ship structures have attracted a lot of theoretical and experimental studies.

The cross-sectional shape of the bottom of a high speed ship is usually approximated as a wedge [4]. Pioneering work on the water entry of the wedge can be traced back to Von Karman [5] and Wagner [6]. Based on the momentum conservation and the concept of added mass, Von Karman performed the theoretical investigation of the hydrodynamic loads acting on a wedge [5]. Wagner refined the model of Von Karman by taking into consideration the local rise of thewater surface during the water impact [6]. Neglecting the effect of gravity and viscosity, Dobrovol'skaya derived the similarity solution for the water entry of symmetrical infinite wedges with a constant velocity [7]. Zhao and Faltinsen [8] 
improved on Dobrovol'skaya's results and presented reliable results for dead-rise angles, down to $4^{\circ}$. Wang and Faltinsen [9] further presented reliable results for dead-rise angles, down to $1^{\circ}$. Kamath illustrated the water impact problem of a symmetrical wedge with the open source computational fluid dynamics (CFD) model REEF3D [10]. The numerical results are in good agreement with the experimental data reported by Yettou et al. [11]. Considering that the presence of the ground may influence the hydrodynamic loading, Jalalisendi et al. [12] carried out freefall experiments of a wedge in finite water depth to investigate shallow water entry. Panciroli et al. systematically performed freefall drop tests of two groups of curved rigid wedges to investigate the role of the curvature on the impact dynamics [13]. The test data has been used to verify the numerical simulation of the water entry of the curved wedges in Yu et al. [14]. Barjasteh et al. presented an experimental study on the water entry of asymmetric wedges and the effects of parameters (including initial dead-rise angle, inclination angle and impact speed) were discussed [15]. Chen et al. investigated the effect of ice on impact loads during the water entry of a wedge by using both CFD and a Wagner-type theoretical model [16].

Compared to the wedge section, the curvature of the bowflare ship section is more complicated. Aarsnes performed the drop tests of a bow-flare ship section [17]. Five different roll angles were considered in the tests. For each roll angle, the test model was dropped from different drop heights. The total test model was divided into three parts: one measuring section with a dummy section on each side. Impact forces, impact pressures and vertical accelerations were measured in the tests. In subsequent studies, many numerical methods were validated using these tests, including the Boundary Element Method [18-19], the Constrained Interpolation Profile method [20], the Arbitrary Lagrangian-Eulerian method [21], and the Finite Volume Method [22]. Free-fall drop tests of a symmetry bow-flare ship section were performed in the Wave Induced Loads on Ships (WILS) Joint Industry Project [23], which was conducted by the Korea Research Institute of Ships and Ocean Engineering (KRISO). Under the proposal of the International Hydrodynamic Committee of the International Society of Offshore and Polar Engineers, comparative studies between different numerical methods and experimental data have been carried out [24-25]. Park et al. [26] carried out a drop test of simple wedge models with fixed dead-rise angles and cross-section models of practical container carrier sterns. The influence of single and twin skeg models on the pressure history is discussed. Guzel [27] conducted drop tests with a bow flare ship section model and a catamaran section model at various impact velocities. Hydrophobicity modifies the water uprising characteristics and energy balances, and reduces the impact loads acting on marine structures during slamming events.

Based on the above review, there were only a few experimental tests on the water entry of ship-like sections in the previous studies. This work was, therefore, motivated by the lack of experimental data suitable for ship-like sections with an obvious bulb. Reasonable experimental data are helpful to the establishment and validation of the numerical model. The present aim is to analyse the slamming characteristics (i.e. pressure time history, impact loads) of the ship-like section by experimental and numerical study. For the ship-like section with an obvious bulbous bow, the flow separation may occur at the location of the bulbous bow, and then the separated free surface impacts on the ship section again. During the secondary slamming process, a gas-filled cavity will form between the ship section and the separated free surface, making the flow field around the section complicated. For the ship-like sections in the previous tests of Aarsnes [17] and MOERI [23], the size of the bulbous bow was small and no cavities (or only small cavities) appeared during water entry. In the present study, the drop test of a ship-like section with an obvious bulbous bow is carried out and a reasonable numerical model is established by using the finite volume method. Then, the influence of bulbous bow on hydrodynamic impact loads acting on bow-flare sections is numerically studied.

\section{EXPERIMENT SETUP CONFIGURATION AND MODELS}

In order to ensure the water-entry attitude of the model, the free-fall drop test was carried out in the test rig shown in Fig. 1. Four guide rails, vertical to the still water surface, were installed in the test rig. The model shelf connected with the guide rail could slide freely along the guide rail. By fixing the test model with the model shelf, the velocity direction of the model was guaranteed to be vertical to the water surface.

Fig. 2 shows the state of the test model installed in the test rig. Fig. 3 shows the model profile and installation position of the pressure sensors. The profile of the model was unchanged along the length direction. The width and length of the model were $1500 \mathrm{~mm}$ and $900 \mathrm{~mm}$, respectively and the mass of the model was $477 \mathrm{~kg}$. Two thin plates $(5 \mathrm{~mm})$ were installed at both ends of the model to ensure that the flow field during the impact process was approximately two-dimensional [28]. The outer plate of the model was $5 \mathrm{~mm}$ thick steel plate with supporting structures inside the model, so that the test model can be regarded as a rigid body.

Six pressure sensors (HM91, German HELM Company) were installed in the test model and the test surface of the pressure sensor was approximately equal to the outer surface of the model [29]. The positions of P1-P5 were equidistant in the bow-flared area. The measurement range of the pressure sensor was $50 \mathrm{kPa}$. The diameter and natural frequency of the pressure sensor was $8 \mathrm{~mm}$ and $150 \mathrm{kHz}$, respectively. A displacement sensor (PT1DN, American Celesco Company) was installed in the test model. The measurement range of the displacement sensor was $6.3 \mathrm{~m}$. The displacement of the model and hydrodynamic impact pressure acting on the model are collected synchronously, and the sampling frequency of the pressure and the displacement signals set to $10 \mathrm{kHz}$ [28-29]. All measured signals are automatically converted into corresponding units of measured variables through the 
calibration factors that were input into the DAQ software prior to the tests and collected through a data acquisition system DH5902.

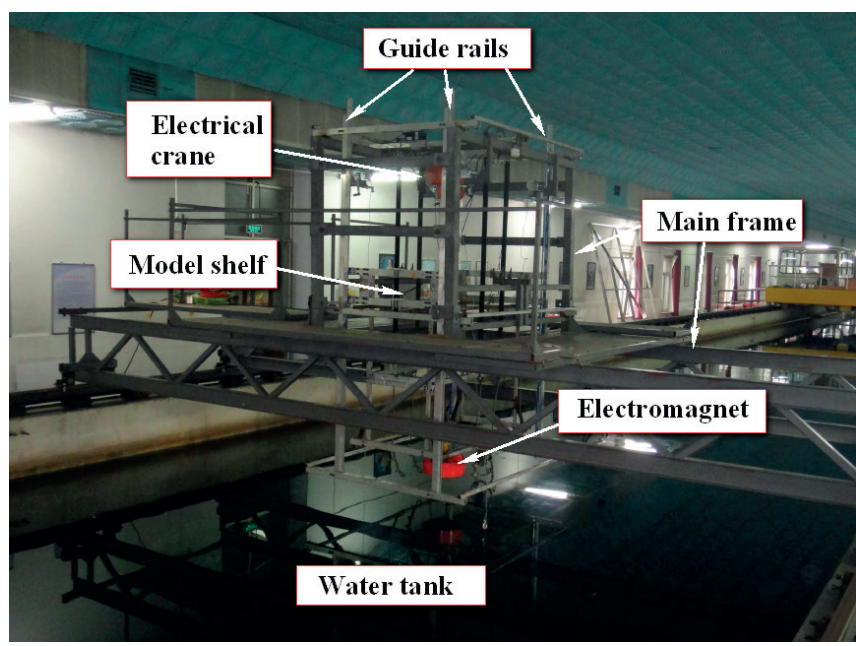

Fig. 1. The test rig

According to the initial drop height and displacement curve of the model, the time when the lowest point of the model touches the still water surface can be determined and is defined as $t=0$. The velocity of the model at $t=0$ is defined as the initial velocity of the water entry in the present study. By differentiating the displacement of the model with time, the initial velocity of the model with different drop heights was obtained.

\section{EXPERIMENTAL RESULTS}

The impact velocity during the free-fall water entry can be adjusted by changing the drop height of the model. The initial impact velocities of the model in the test were 2.648, 3.074 and $3.448 \mathrm{~m} / \mathrm{s}$, respectively, corresponding to three different drop heights. In order to ensure the stability of the test results, at least three repeated tests were carried out for each test condition. Fig. 4 shows the results of three repeated tests for the case with the initial impact velocity $\mathrm{V}_{0}=3.448 \mathrm{~m} / \mathrm{s}$. Although there are a few deviations in the test data of the three same test conditions, the test data has good repeatability in general.

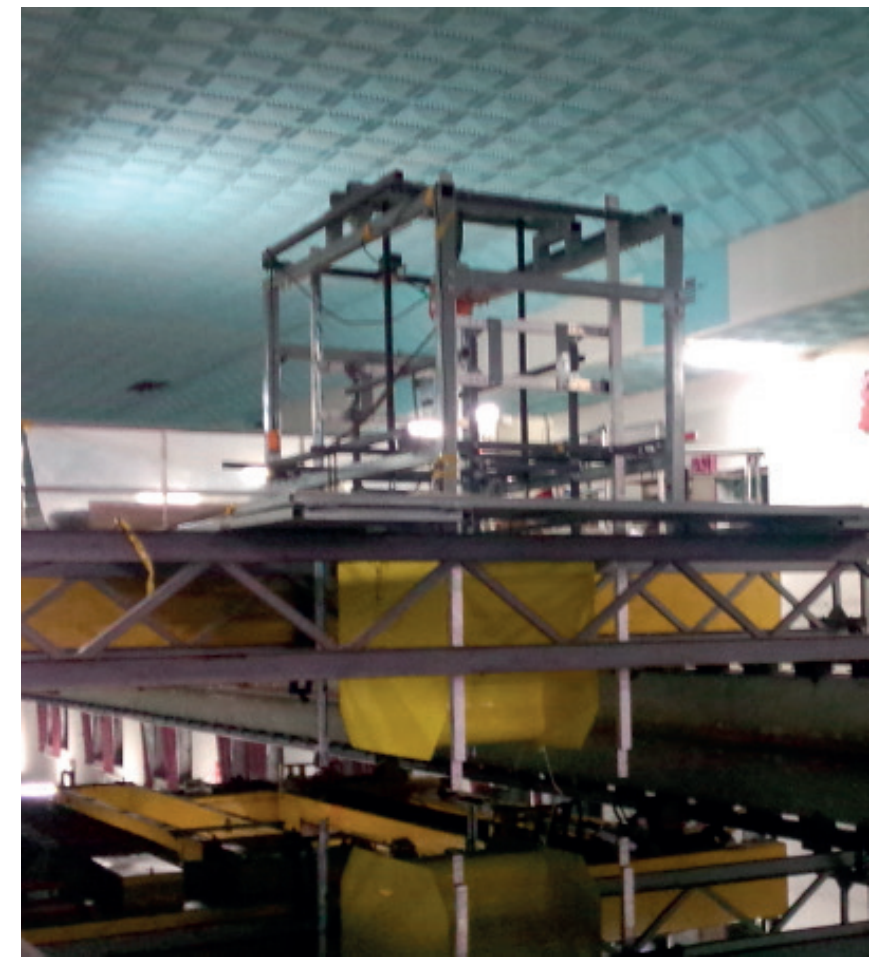

Fig. 2. The state of the test model installed in the test rig

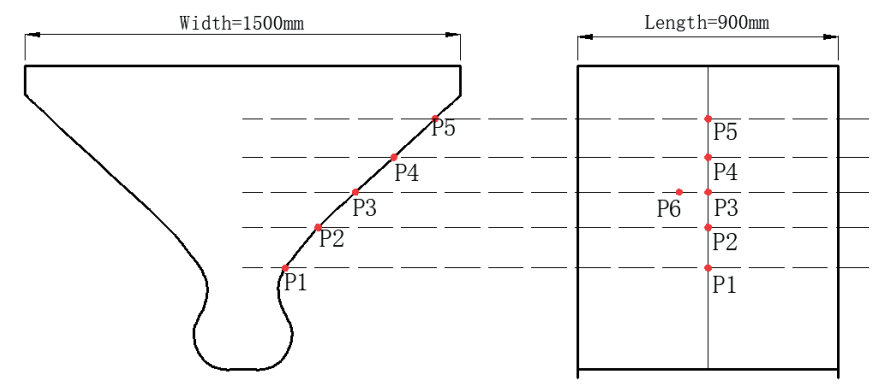

Fig. 3. Model profile and installation position of pressure sensors 


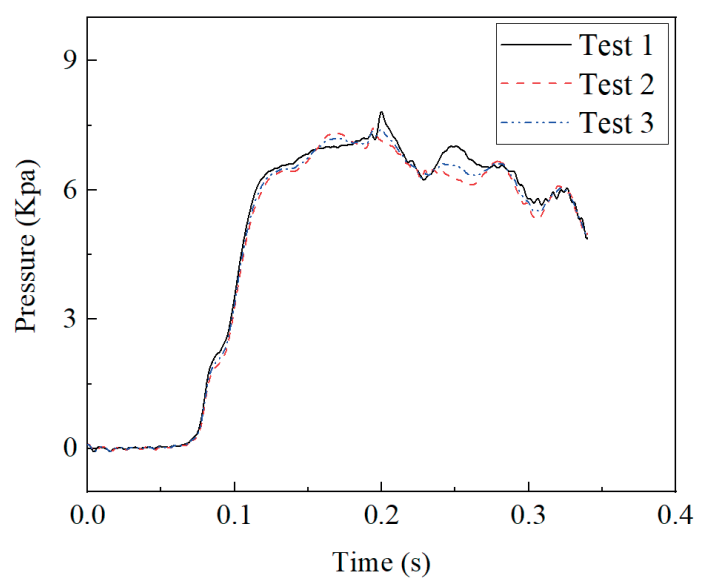

(a)

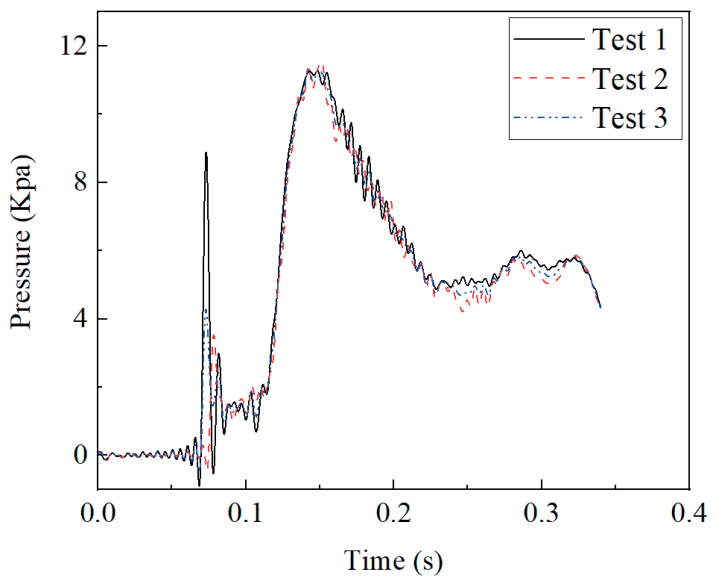

(c)

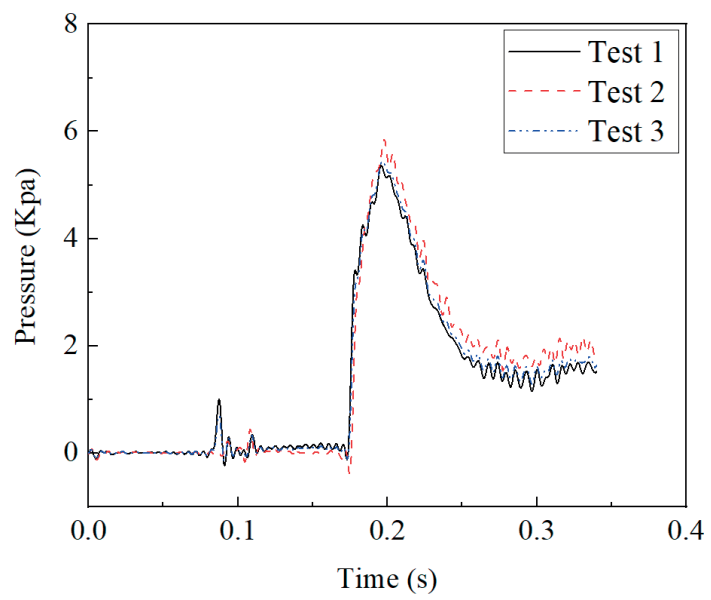

(e)

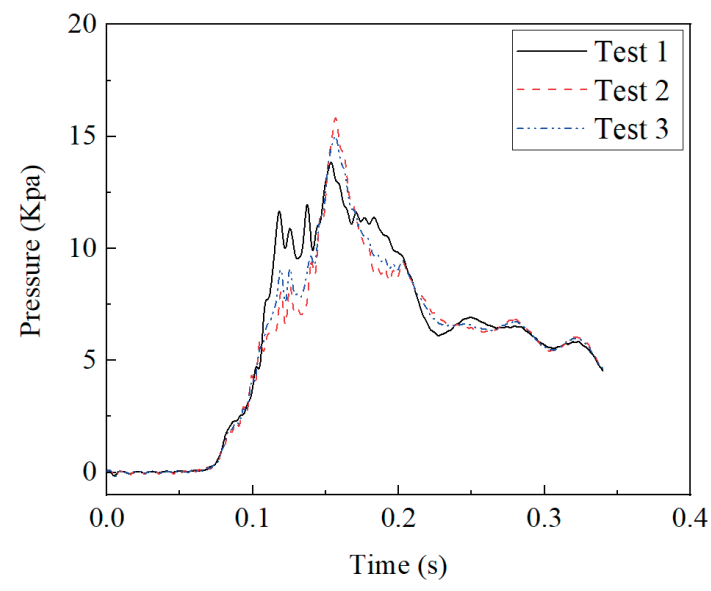

(b)

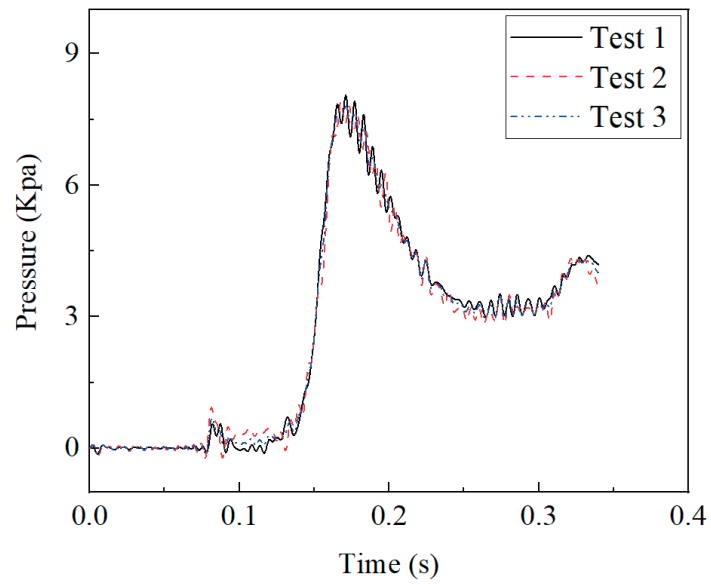

(d)

Fig. 4. The results of three repeated tests for the case with the initial impact velocity V0=3.448m/s: (a) P1; (b) P2; (c) P3; (d) P4; (e) P5

Fig. 5 shows the change of flow field during the test. As shown in Fig.5(a), before the bulb entered the water, the motion of the model is similar to a free-falling body. As the model continued to move downward, it began to enter the water and was subjected to the reaction force of the fluid. At this moment, the bulb slamming lead to the flow separation of the fluid (Fig.5(b)). It can be seen that the flow field outside the thin plate at both ends of the model is less disturbed, and the water splashes mainly along the two sides of the model section. Then, the water jet impacted on the flare of the section, as shown in Fig.5(c). With the further falling of the model, a large amount of water escaped after the flare slamming, as shown in Fig.5(d). 
Fig. 6 shows the comparison of impact pressures at the locations $\mathrm{P} 3$ and P6, which have the same height but different longitudinal positions. It can be seen that the impact pressure in the middle part of the model varies very little along the

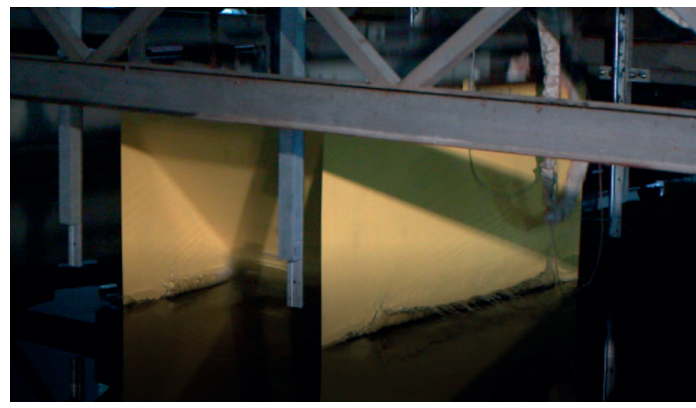

(a)

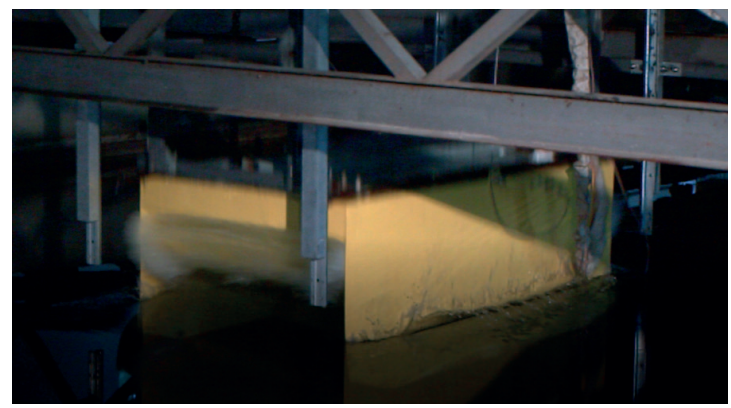

(c)

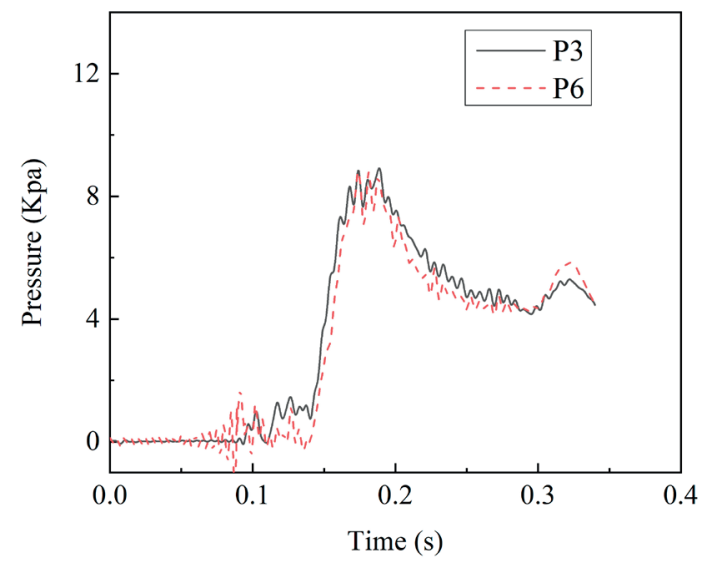

(a)

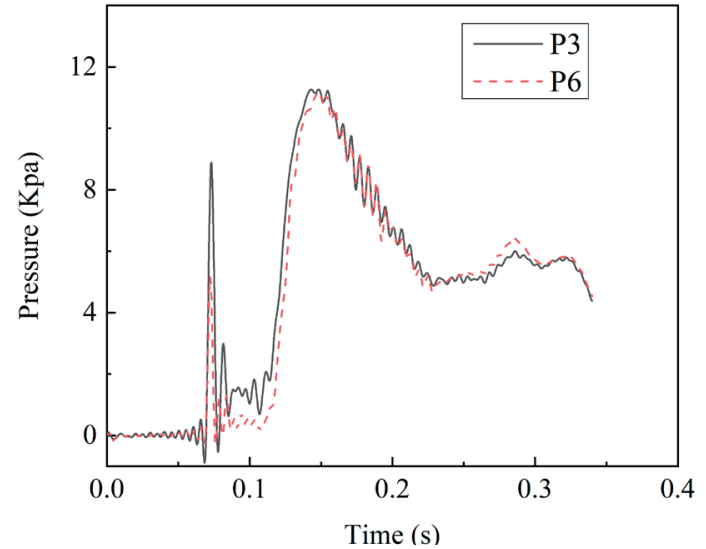

(c) length direction, which indicates that the flow field in the middle part of the model is similar to the water entry of the two-dimensional section.

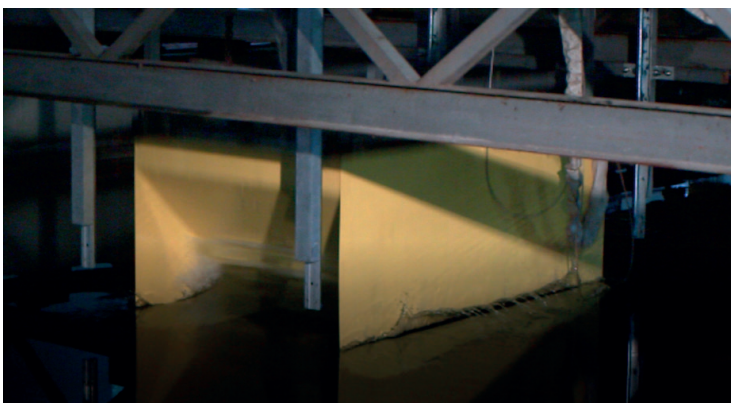

(b)

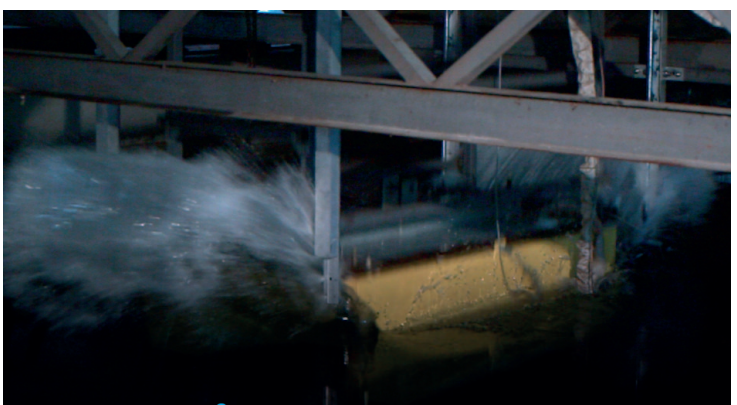

(d)

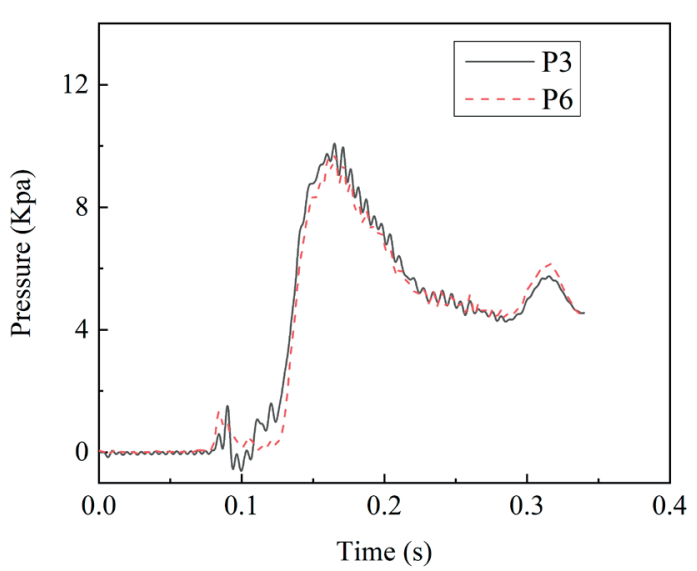

(b)

Fig. 6. The comparison of impact pressures at locations $P 3$ and $P 6$ for different initial impact velocities: (a) V0=2.648 m/s; (b) V0=3.0748 m/s; (c) V0=3.448 m/s 
Fig. 7 shows the impact pressure results with different initial impact velocities. Because of the influence of flow separation near the bulbous bow, the pressure sensors at P1 and $\mathrm{P} 2$ are almost simultaneously stimulated. Flow separation and gas trapping occur near the bulbous bow during the impact of the ship-like section due to the relatively appropriate entry velocity. The low velocity entrances cannot bring the water to separate and so, when the water entry velocity is high, the separation of flow probably skips P1 and P2 and directly

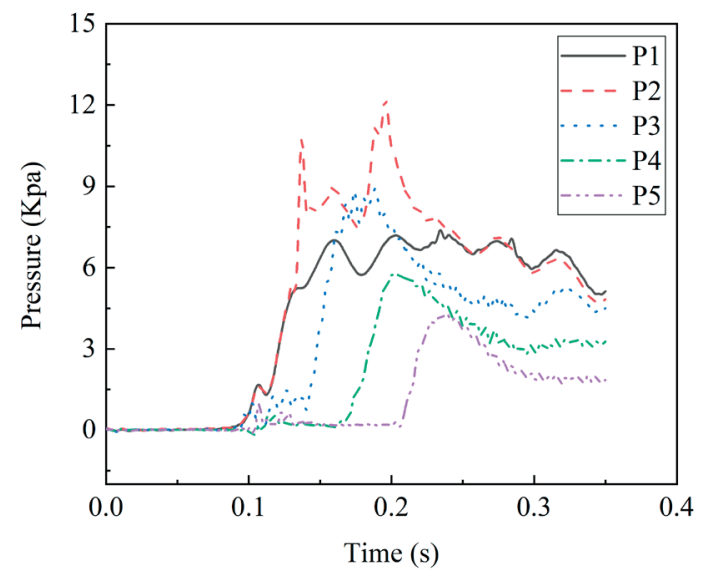

a)

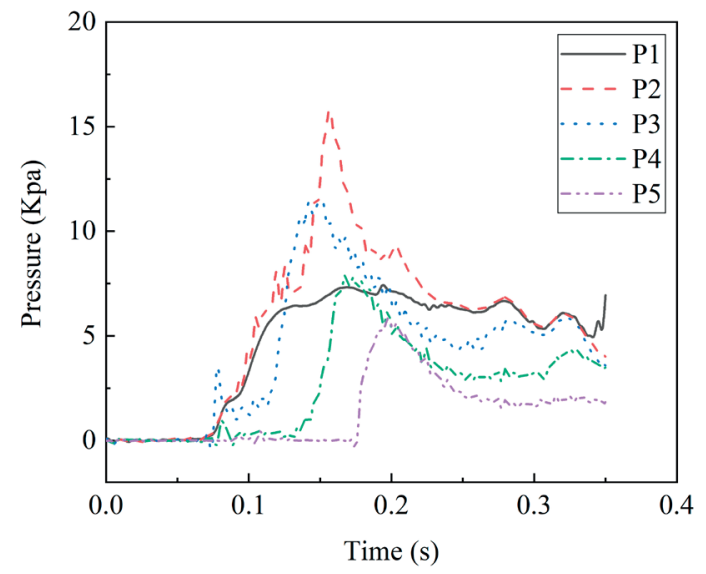

c) hits the vicinity of $\mathrm{P} 3$ and $\mathrm{P} 4$. $\mathrm{P} 3$ reaches peak value earlier than $\mathrm{P} 1$ and $\mathrm{P} 2$ at $\mathrm{V}_{0}=3.448 \mathrm{~m} / \mathrm{s}$ in Fig.7(c). The peak pressure time at P3 is delayed in other cases (Fig.7(a) and Fig.7(b)) under different water entry velocities; this also verifies the relationships between the water entry velocities and the flow separation characteristics. After the flow separation occurs, the water surface gradually rises along the hull surface and the pressure sensors at P3, P4 and P5 generate signals in turn, respectively.

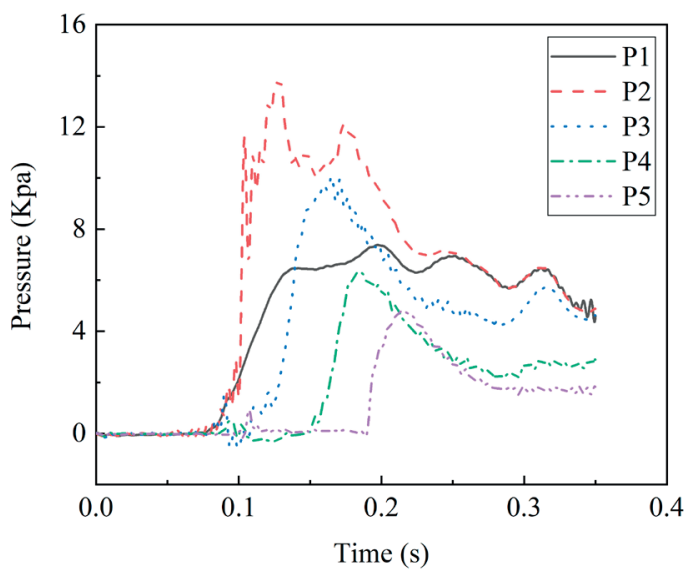

b)

Fig. 7. The impact pressure results with different initial impact velocities: (a) V0=2.648 m/s; (b) V0=3.0748 m/s; (c) V0=3.448 m/s

\section{NUMERICAL MODEL}

\section{NUMERICAL METHODS}

The water entry of the ship-like section is numerically studied by using the commercial Computational Fluid Dynamics (CFD) solver StarCCM+ software [30]. The two fluids (water and air) are assumed to be immiscible and incompressible [22] [25]. The interface between air and water is captured by using the VOF technique and the High-Resolution Interface Capturing (HRIC) scheme [3132]. The VOF technique has been illustrated in the author's previous work [33]. Temporal integration is carried out by using the Euler implicit scheme. The governing equations are discretised by the central difference scheme in space except the convection term, which uses a second-order upwind scheme. The Segregated Flow solver based on the SemiImplicit Method for Pressure-Linked Equations (SIMPLE) algorithm is used to solve the pressure and velocity coupling problem during the water entry. The motion of the grid around the ship section is numerically realised by using the overset mesh method, and the transfer of physical quantities between the overset zone and the background zone is realised by using the linear interpolation method. 


\section{COMPUTATIONAL OVERVIEW}

The ship-like section considered in the present study is symmetrical and its motion is limited to the vertical direction. Therefore, only half of the model is established. As shown in Fig. 8, the computational domain is rectangular and the vertices of the rectangle are marked $A, B, C$ and $\mathrm{D}$, respectively. A Cartesian coordinate system OXY is introduced to describe the numerical model. The OX axis is located at the undisturbed water surface and the OY axis lies in the symmetrical axis of the bow-flared sections. The dimension of the computational domain in the XY-plane is described by L1, $\mathrm{L} 2$ and $\mathrm{H}$, respectively. $\mathrm{W}$ is the half-width of the bow-flared sections. Referring to the discussion on the size of the computational domain [32] [34], the lengths of L1, $\mathrm{L} 2$ and $\mathrm{H}$ are set to $8 \mathrm{~W}, 4 \mathrm{~W}$ and $10 \mathrm{~W}$, respectively.

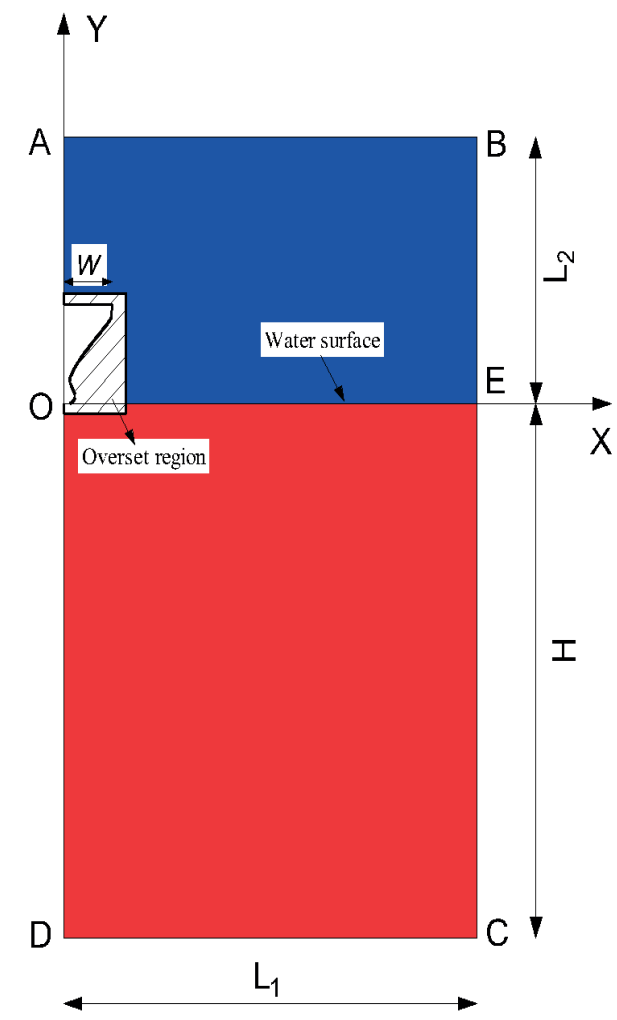

Fig. 8. The schematic diagram of the computational domain

The boundary conditions of the numerical model are set as follows. The boundary condition of 'AB' is set to pressure outlet. Only air is allowed to exit the domain. The boundary conditions of 'BC' and 'CD' are set to velocity inlet, where the velocity and the composition of field components (air and water) are specified. Only water is allowed to enter into the boundary 'CD'. The boundary condition of 'AD' is set to symmetry boundary. The boundary condition of the ship section is set to no-slip wall. Fig. 9(a) shows the mesh view of the global domain. An overset mesh is applied to the model and it is shown in black in Fig. 9(a). In order to simulate the interaction between the section and the water accurately, fine mesh is assigned to the region where the section may pass. Fig. 9(b) shows the fine mesh near the section.

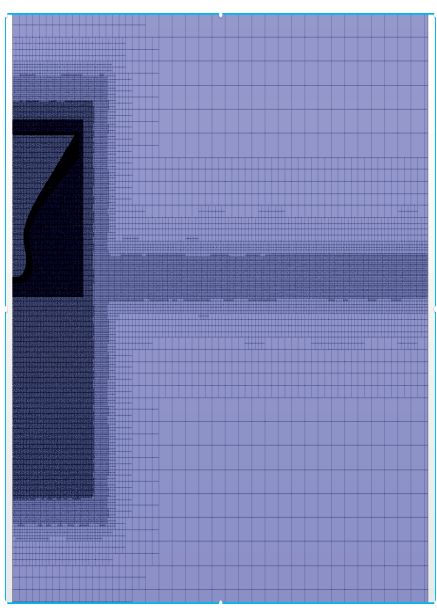

(a)

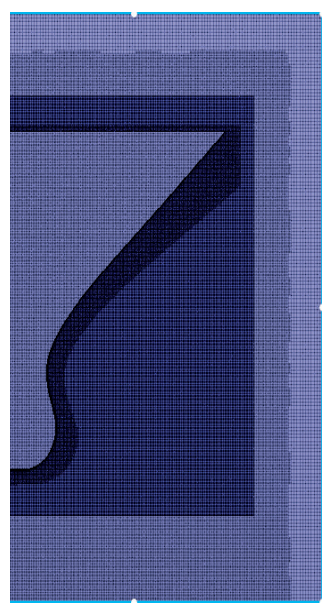

(b)
Fig. 9. Mesh views: (a) global domain; (b) fine mesh near the section

\section{CONVERGENCE STUDY}

The studies for evaluating the effects of grid resolution and the time step on the calculated results were carried out and the initial impact velocity of the model was set to $\mathrm{V}_{0}=3.448 \mathrm{~m} / \mathrm{s}$. The K-Epsilon turbulence model was selected as the flow model. The effects of different flow models are discussed in Section 5.1 and the main characteristics of four different mesh configurations are shown in Table 1. Fig. 10 shows impact pressures with different mesh densities. The time step was set to $\Delta t=2.5 \times 10^{-4} \mathrm{~s}$. It can be seen that the results of the coarse and coarser mesh configurations are obviously different from the other two mesh configurations, especially for the location P1. The results of medium and fine mesh configurations show good agreement, although there is still a small deviation. Fig. 11 shows impact pressures with different time steps. The medium mesh configuration was chosen. It can be seen that the results of $\Delta t=5 \times 10^{-4} \mathrm{~s}$ and $\Delta \mathrm{t}=2.5 \times 10^{-4} \mathrm{~s}$ are in good agreement for all of the five locations. The time step was set to $\Delta \mathrm{t}=2.5 \times 10^{-4} \mathrm{~s}$ in the following simulations.

Tab. 1. Summary of the element count with different mesh densities

\begin{tabular}{|c|c|c|c|}
\hline \multirow{2}{*}{$\begin{array}{c}\text { Mesh } \\
\text { configuration }\end{array}$} & \multicolumn{3}{|c|}{ Number of elements } \\
\cline { 2 - 4 } & Background & Overset & Total \\
\hline coarser & 47278 & 9469 & 56747 \\
\hline coarse & 132835 & 68375 & 201210 \\
\hline medium & 132835 & 360663 & 493498 \\
\hline fine & 459661 & 473947 & 933608 \\
\hline
\end{tabular}




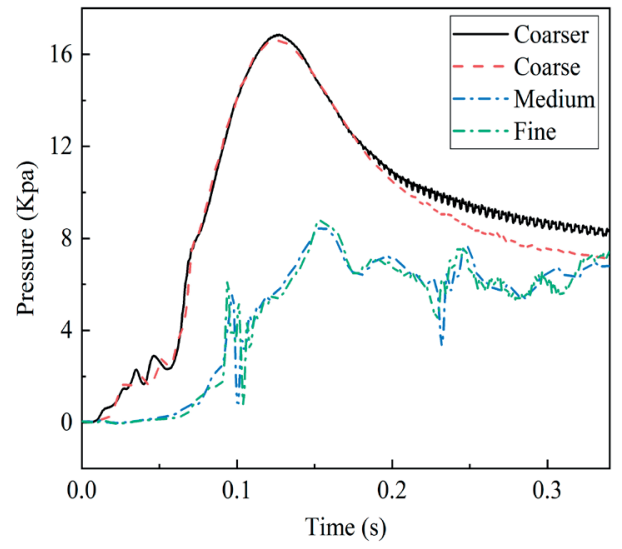

(a)

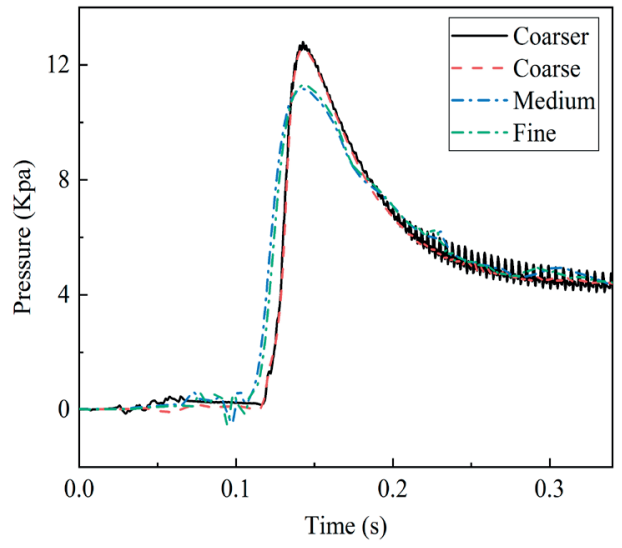

(c)

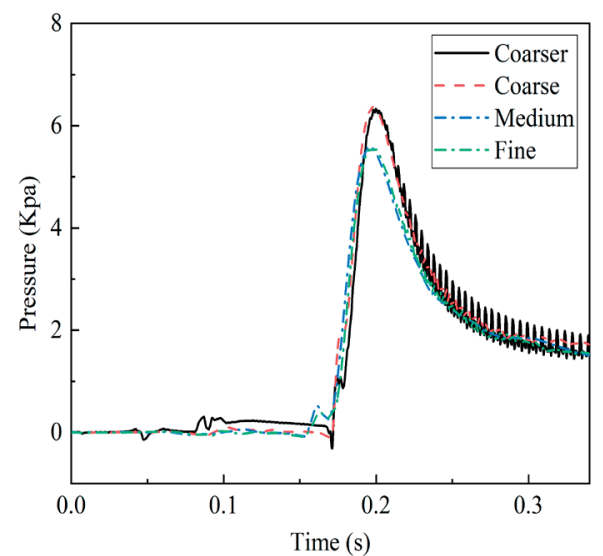

(e)

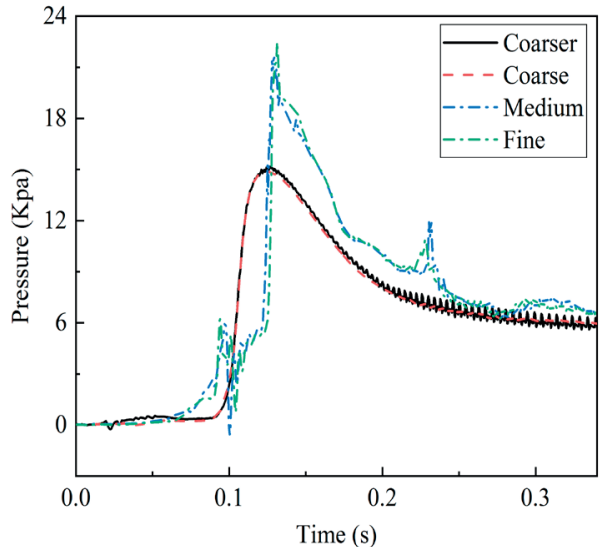

(b)

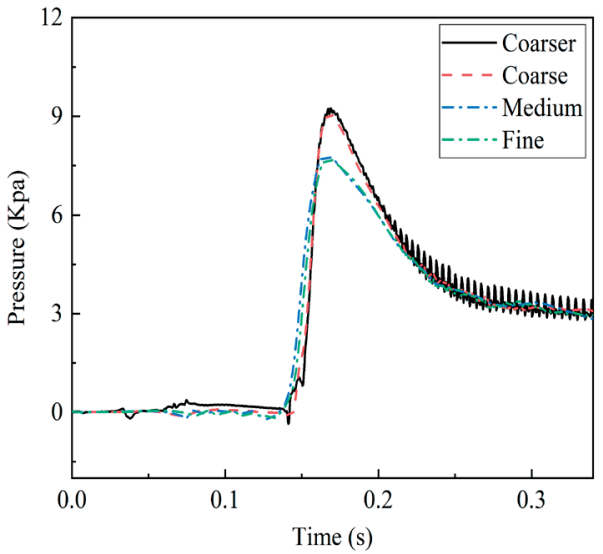

(d)

Fig. 10. Impact pressures with different mesh densities: (a) P1; (b) P2; (c) P3; (d) P4; (e) P5 


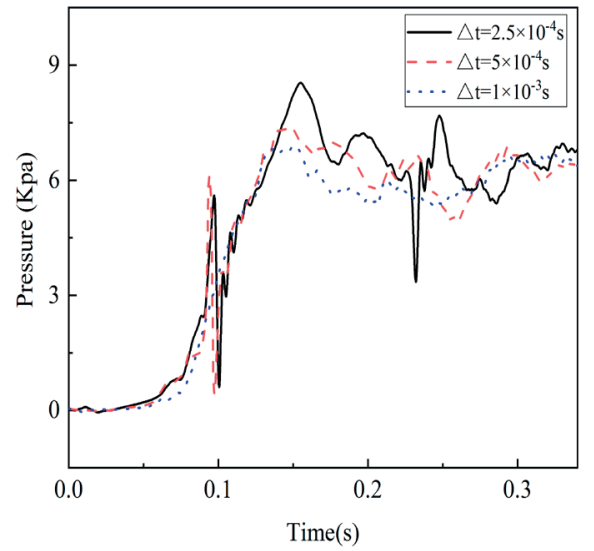

(a)

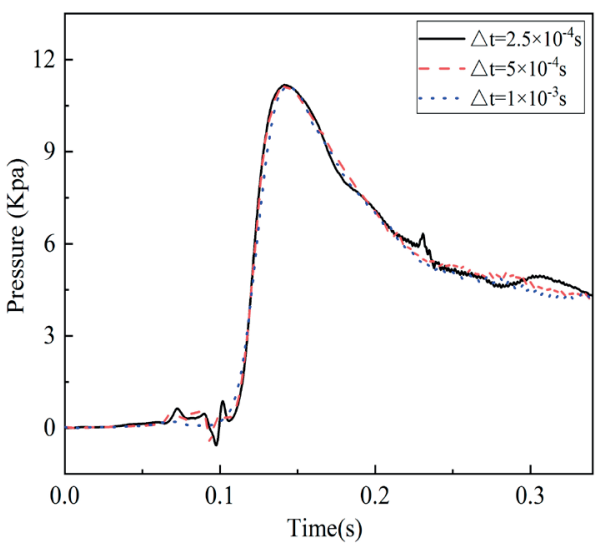

(c)

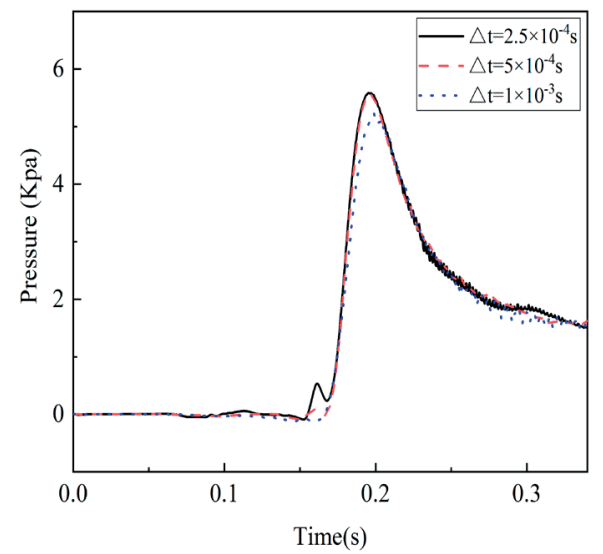

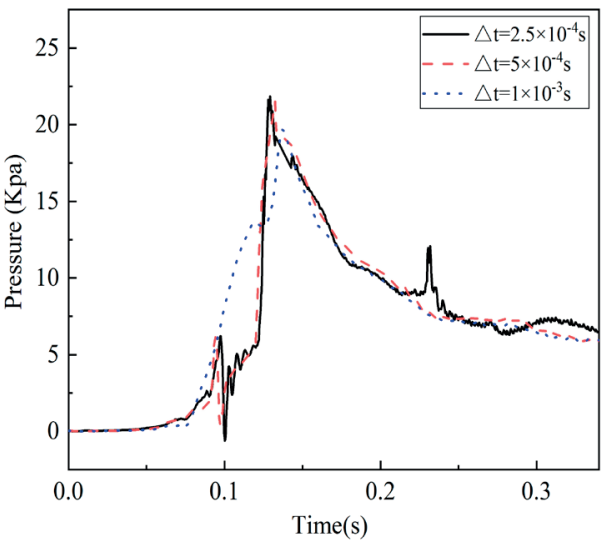

(b)

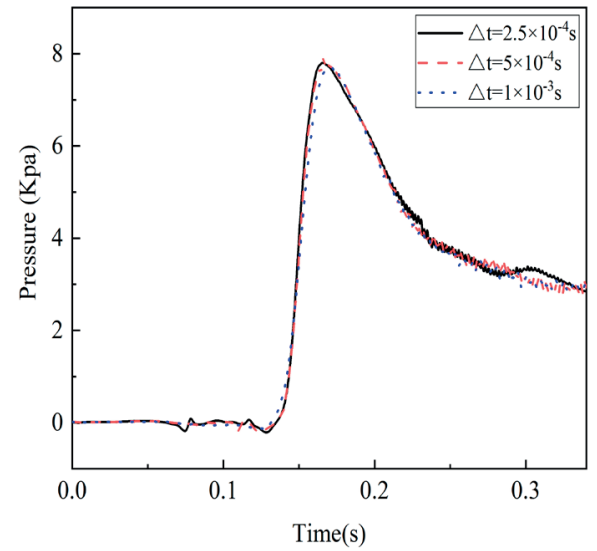

(d)

(e)

Fig. 11. Impact pressures with different time steps: (a) P1; (b) P2; (c) P3; (d) P4; (e) P5

\section{RESULTS AND DISCUSSION}

\section{CONFRONTATION OF NUMERICAL RESULTS WITH EXPERIMENTAL DATA}

In the numerical simulation of water entry problems, different flow models have been adopted in the previous studies [22] [35]. For the water entry of a two-dimensional wedge, Johannessen compared the impact pressure and the impact force of different flow models by using the CFD solver StarCCM+, and found that the selection of flow models has little effect on the impact loads. In the present study, several different flow models in the CFD solver StarCCM+ were used to simulate the water entry of the ship-like section, including the K-Epsilon turbulence model, SST K-Omega turbulence model, Spalart-Allmaras turbulence model and Laminar model. 
(a)

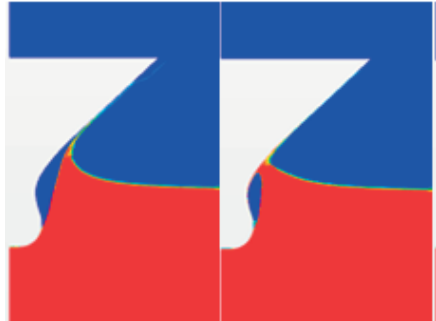

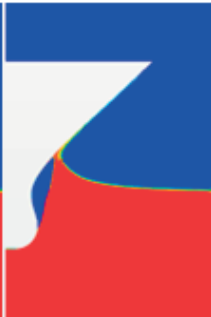

(c)

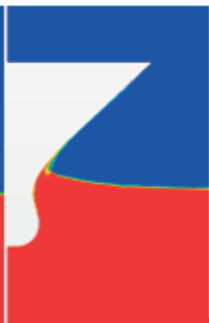

(d)
Fig. 12. The free surface changes of the flow field obtained by using different turbulence models at $t=0.075 \mathrm{~s}$ : (a) Epsilon; (b) K-Omega; (c) S-A;

\section{(d) Laminar}

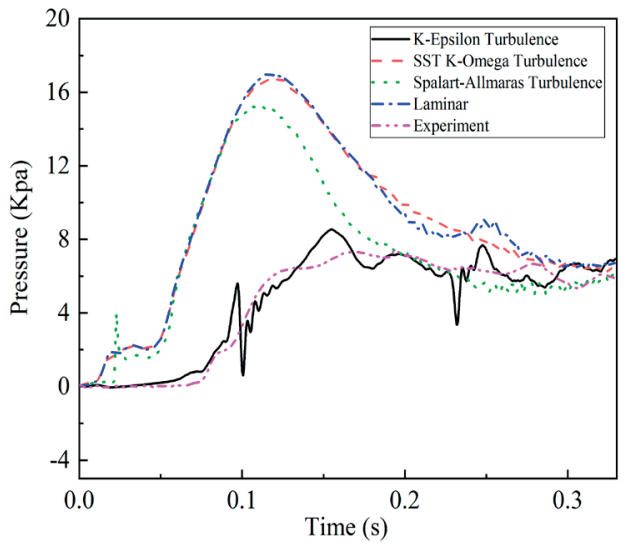

(a)

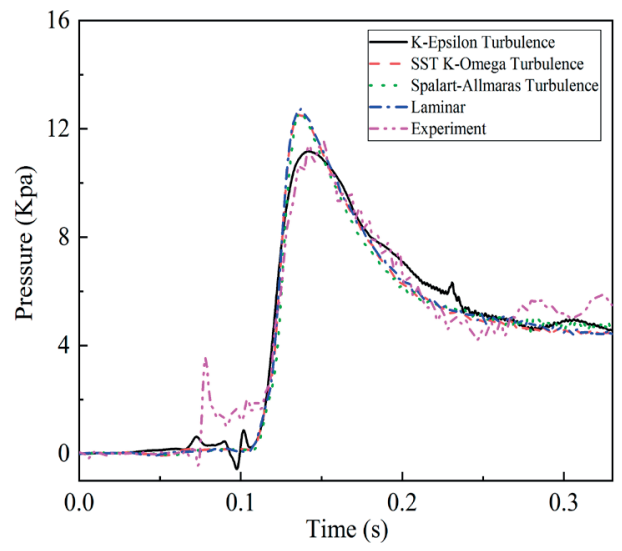

(c)

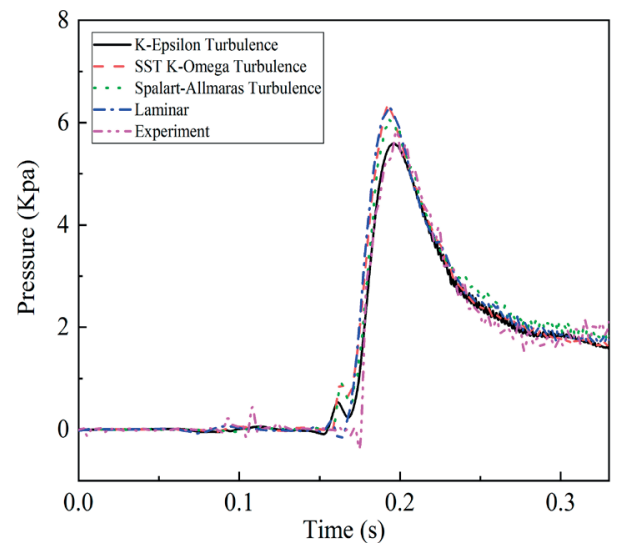

(e)
Fig. 12 shows the free surface changes of the flow field obtained by using different flow models at $\mathrm{t}=0.075 \mathrm{~s}$. It can be seen that the results of three turbulence models show obvious flow separation phenomenon at the position of the bulbous bow. However, the free surface predicted by the laminar flow model rises gradually along the ship section, which is obviously different from the numerical results of turbulence models.

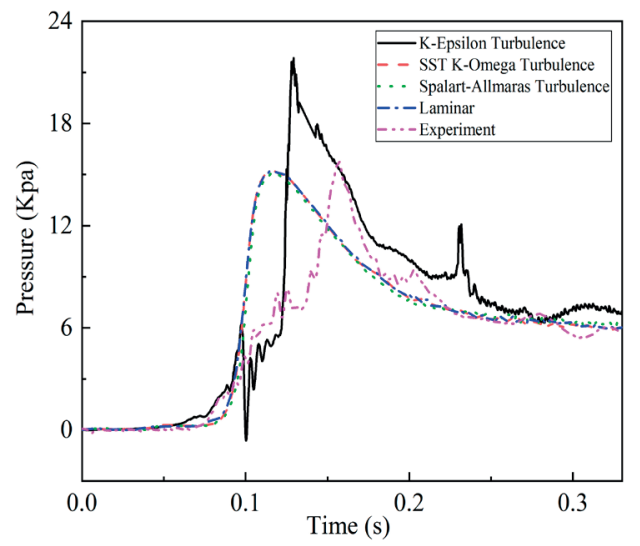

(b)

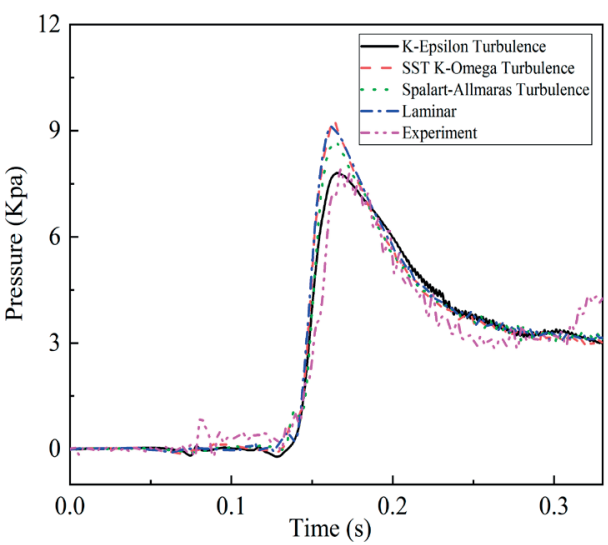

(d)

Fig. 13. The comparison between numerical results and experimental results for the initial impact velocity V0=3.448 m/s: (a) P1; (b) P2; (c) P3; (d) P4; (e) P5 
Fig. 13 shows the comparison between numerical results and experimental results for the initial impact velocity $\mathrm{V}_{0}=3.448 \mathrm{~m} / \mathrm{s}$. For the location $\mathrm{P} 1$, the pressure history predicted by using the laminar flow model generates earlier and the peak value of pressure is larger. This is because there is no flow separation phenomenon in the results of the laminar Model; the water surface contacts the $\mathrm{P} 1$ position more quickly. The numerical oscillation in the results of the SST K-Omega turbulence model and the Spalart-Allmaras turbulence model is more obvious than that of the K-Epsilon turbulence model for location P1. The result of the K-Epsilon turbulence model agrees well with the experimental value.

For the location $\mathrm{P} 2$, the variation trend of the numerical results obtained by using the K-Epsilon turbulence model is closer to that of the experimental value compared with other flow models, especially for the pressure rise stage between $\mathrm{t}=0.1 \mathrm{~s}$ and $\mathrm{t}=0.12 \mathrm{~s}$. But the results of the K-Epsilon turbulence model and the experimental value still have some deviations in the peak value of impact pressure.

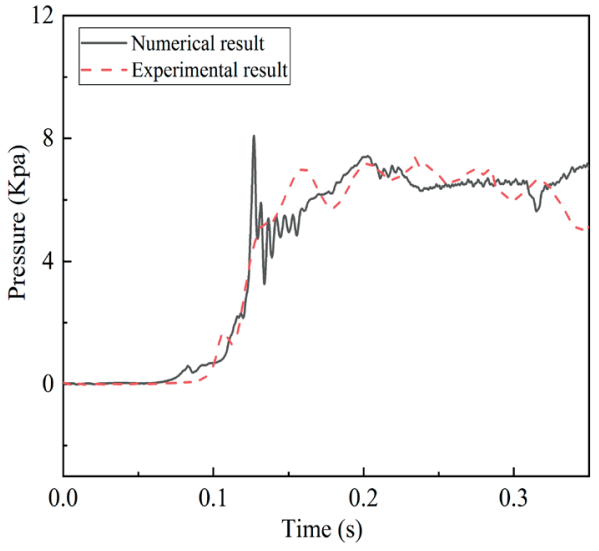

(a)

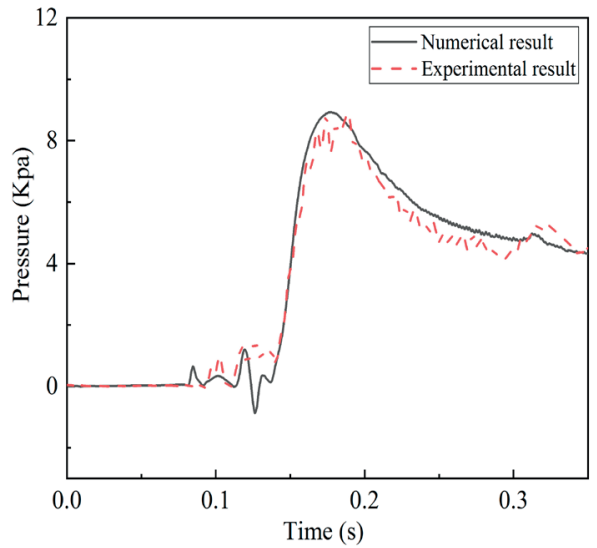

(c)

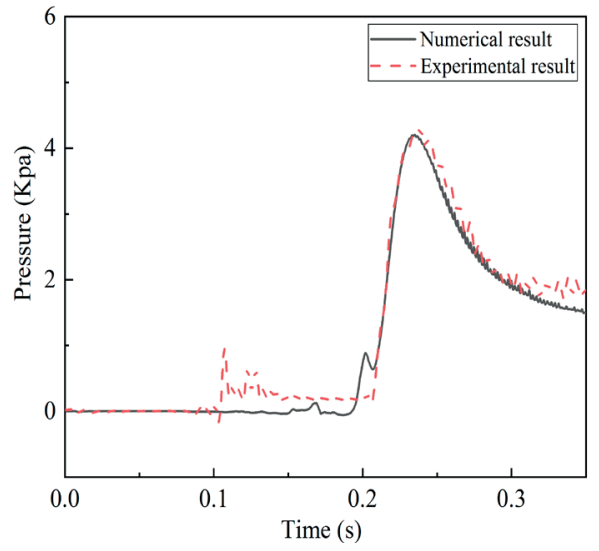

(e)

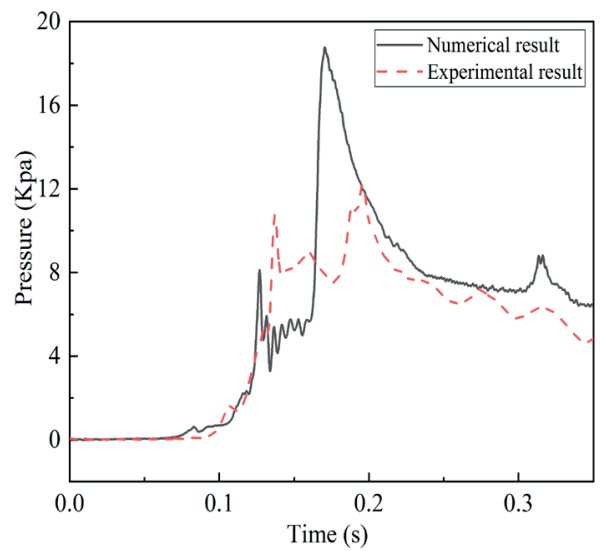

(b)

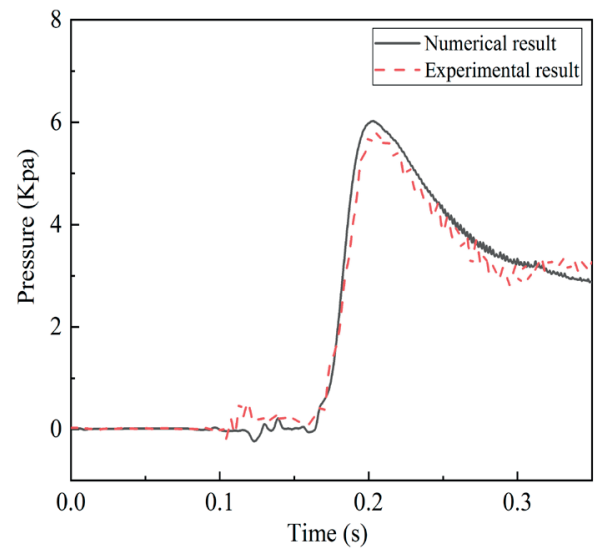

(d)

Fig. 14. The comparison between numerical results and experimental results for the initial impact velocity V0=2.648 m/s: (a) P1; (b) P2; (c) P3; (d) P4; (e) P5 


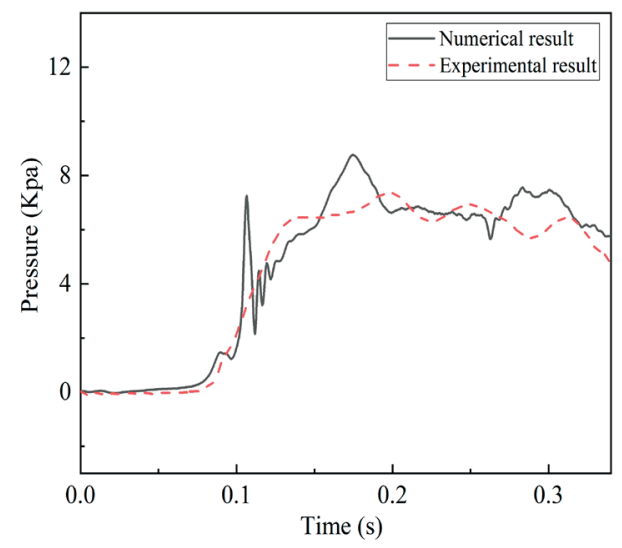

(a)

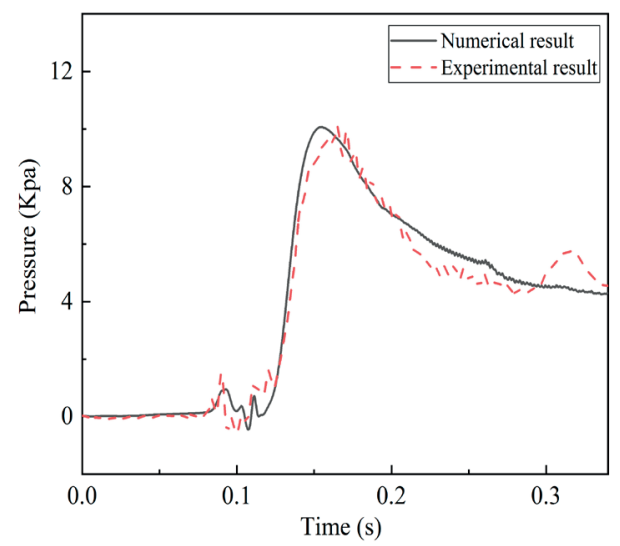

(c)

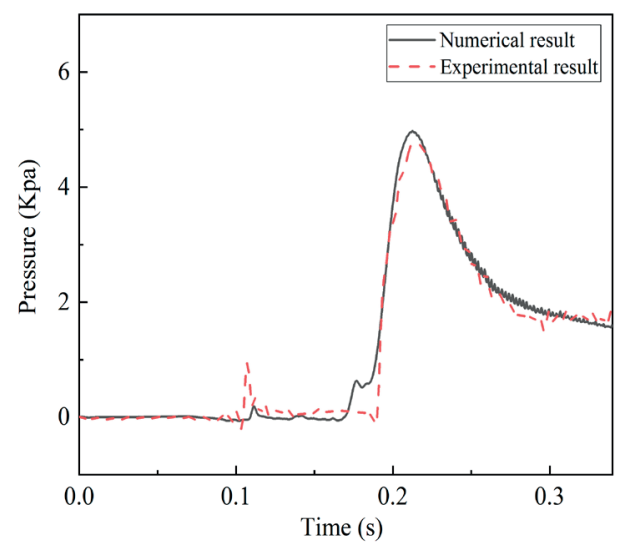

(e)

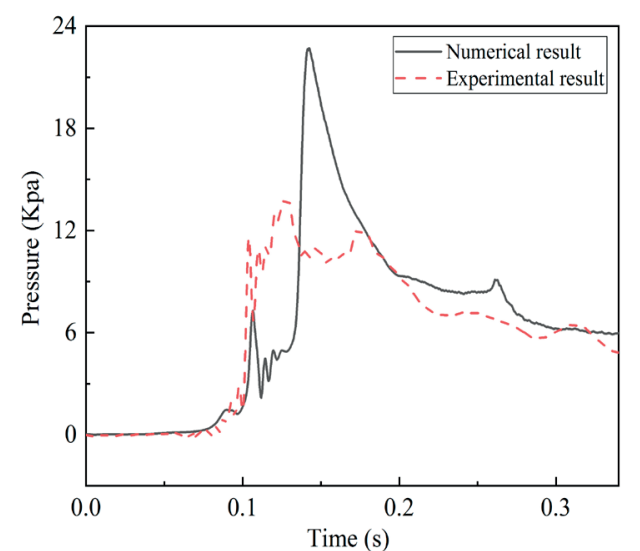

(b)

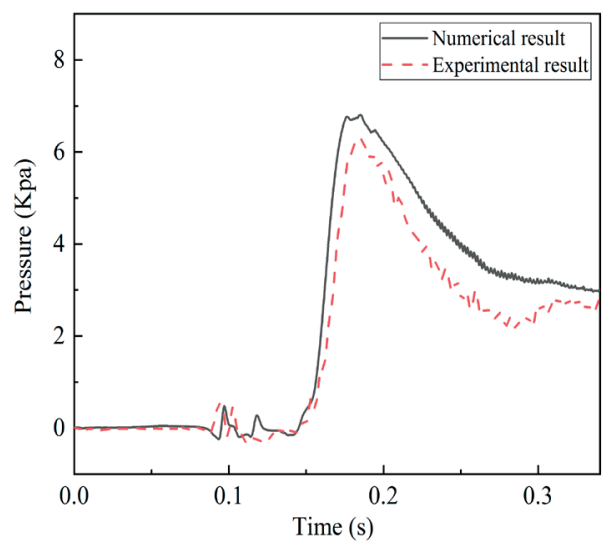

(d)

Fig. 15. The comparison between numerical results and experimental results for the initial impact velocity V0=3.074 $\mathrm{m} / \mathrm{s}$ : (a) P1; (b) P2; (c) P3; (d) P4; (e) P5 
For the locations P3, P4 and P5, the overall deviation of numerically predicted results for different flow models is small. Compared to the numerical results of other flow models, the K-Epsilon turbulence model has the best agreement with the experimental results. For the peak slamming pressure of P3, $\mathrm{P} 4$ and P5, the deviation between the numerical results of the $\mathrm{K}$-Epsilon turbulence model and the experimental values is $1.72 \%, 1.33 \%, 4.34 \%$, respectively.

Fig. 14 and Fig. 15 show the comparisons between numerical and experimental results for $\mathrm{V}_{0}=2.648 \mathrm{~m} / \mathrm{s}$ and $\mathrm{V}_{0}=3.074 \mathrm{~m} / \mathrm{s}$, respectively.

The flow model is set to the K-Epsilon turbulence model. The numerical results are generally in good agreement with the experimental results for different initial impact velocities, except location P2. For location P2, the impact pressure is mainly caused by the secondary impact of the separated liquid on the ship section. In addition, the effect of the air cavity cannot be missed. The peak value of impact pressure (P2), obtained by using numerical methods, is much larger than that of the experimental data. Since the air cavity is important in such a three-dimensional model, due to the bulbous bow, the air effect may be significant [36-37].

\section{INFLUENCE OF BULBOUS BOW ON IMPACT LOADS}

In some studies of ship slamming, the bulbous bow of the original bow-flared section may be simplified [38-39]. Fig. 16 shows the comparison of the original and simplified sections. The profiles of the two sections are the same in the bow-flared area $(y>380 \mathrm{~mm})$. In order to analyse the influence of bulbous bow on the impact loads, a comparative analysis on the water entry of the two sections was carried out. The impact velocity is constant at $4 \mathrm{~m} / \mathrm{s}$. The flow model is set to the K-Epsilon turbulence model. Fig. 17 shows the comparison of the water surface elevation during water entry of two sections. It can be seen that there is obvious flow separation and gas capture phenomena during the water entry of the original section, which cannot be seen in the water entry process of the simplified section.

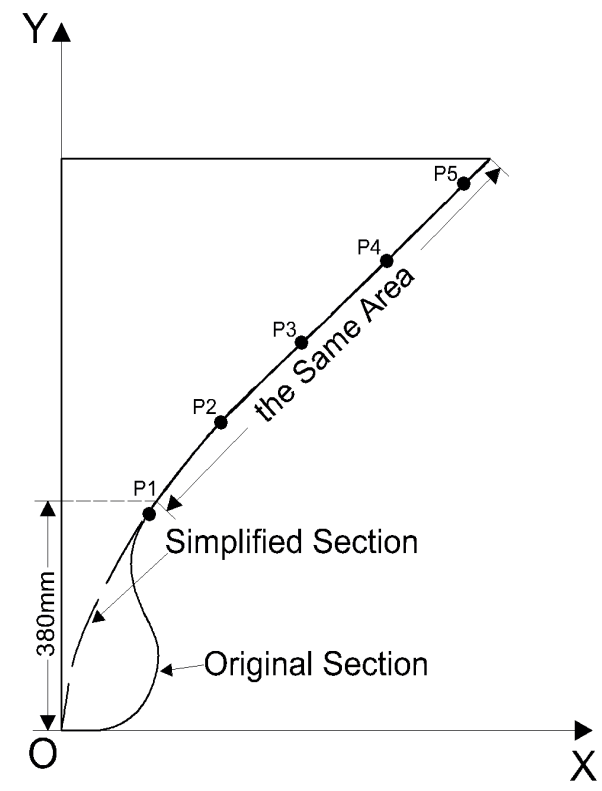

Fig. 16. The comparison of the original and simplified sections

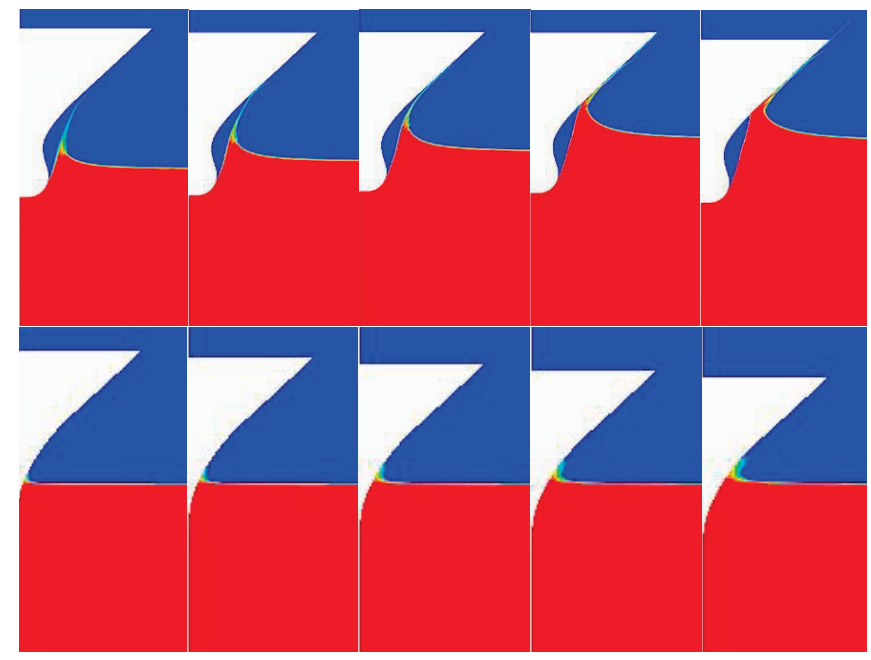

Fig. 17. The comparison of the water surface elevation during water entry of two sections 


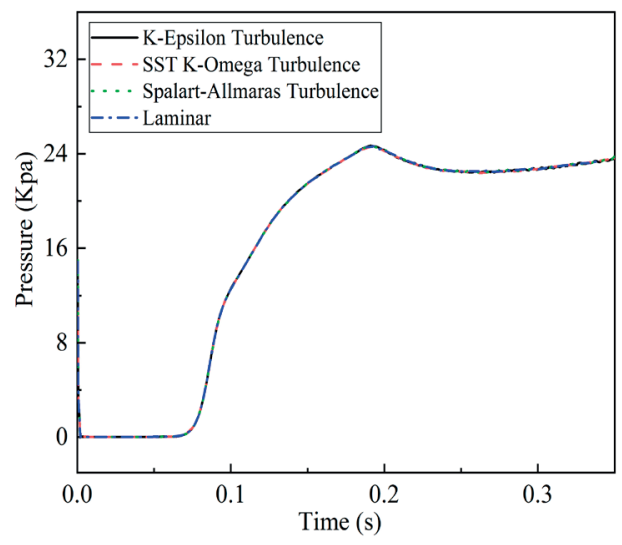

(a)

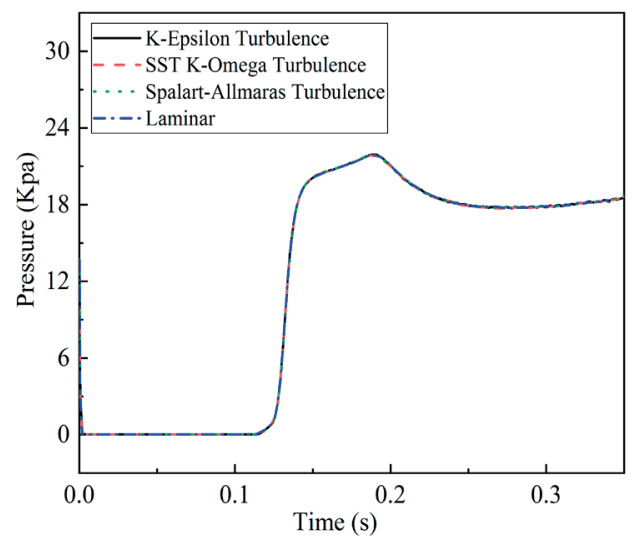

(c)

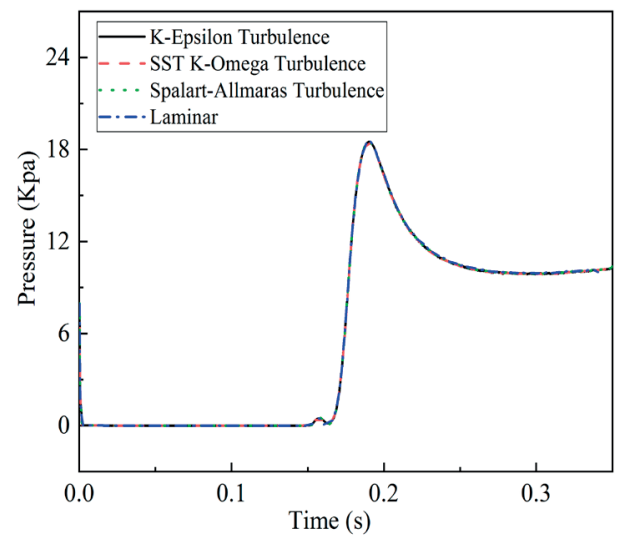

(e)

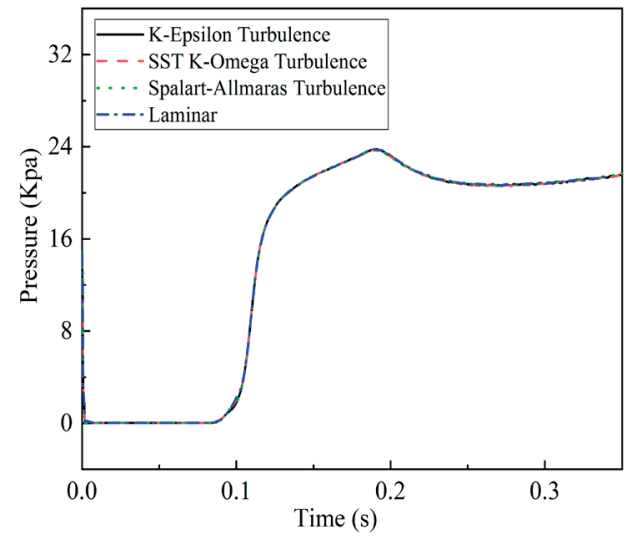

(b)

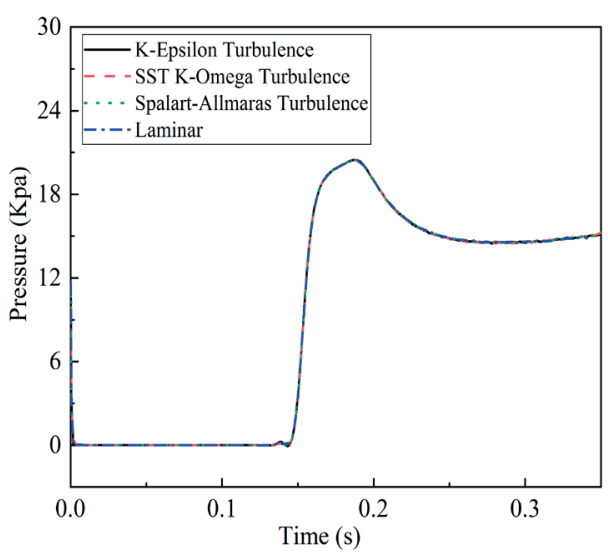

(d)

Fig. 18. Impact pressure of the simplified section obtained by using different flow models: (a) P1; (b) P2; (c) P3; (d) P4; (e) P5 


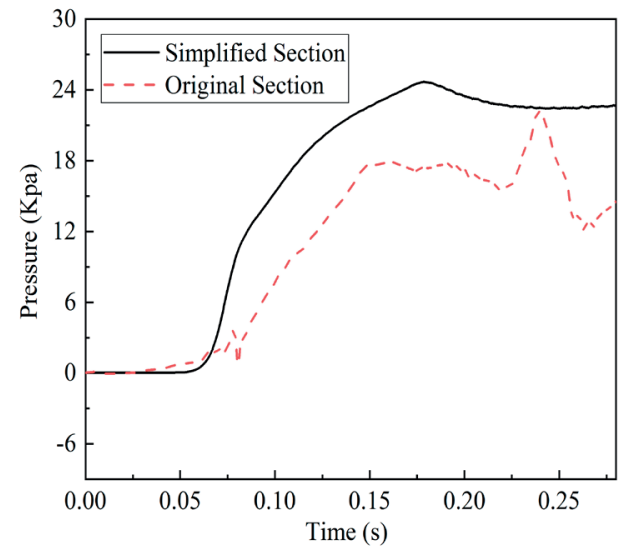

(a)

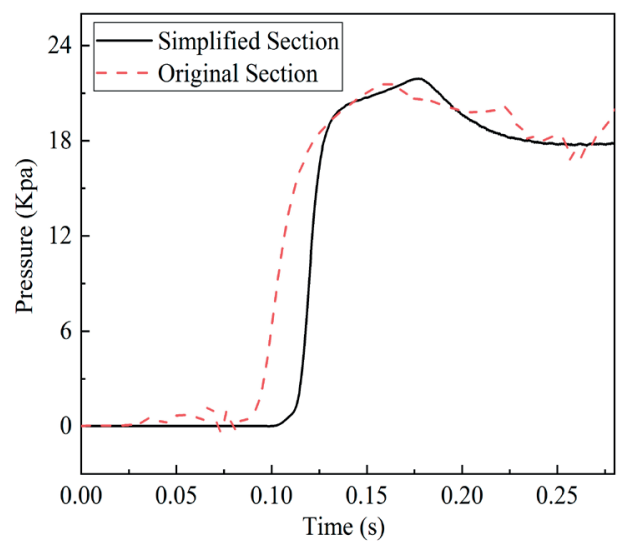

(c)

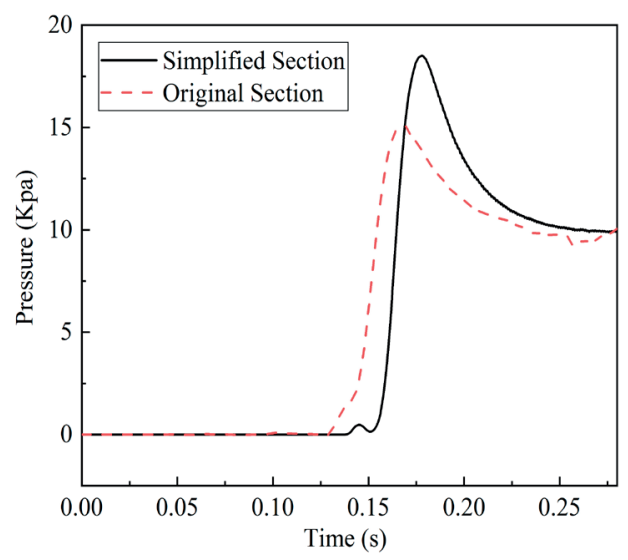

(e)

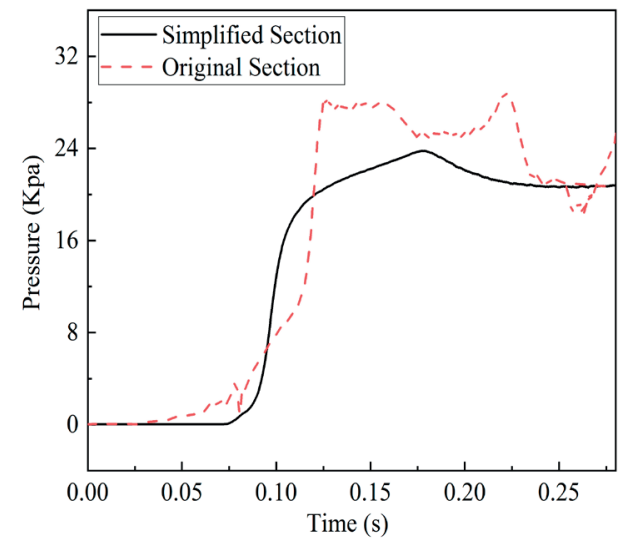

(b)

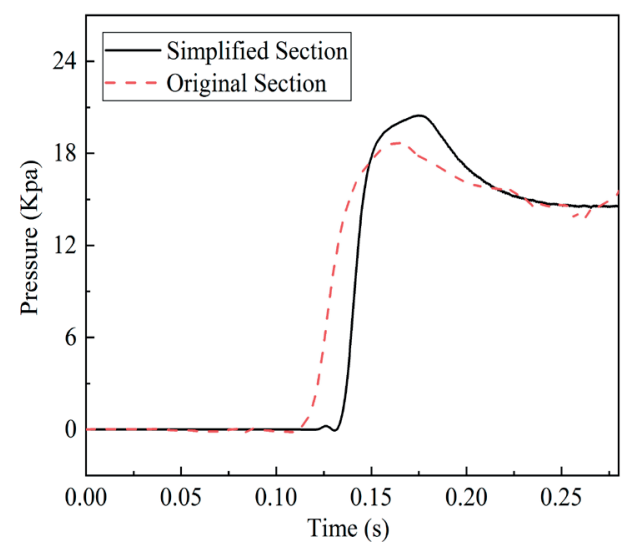

(d)

Fig. 19. The comparison of impact pressure at typical locations: (a) P1; (b) P2; (c) P3; (d) P4; (e) P5 


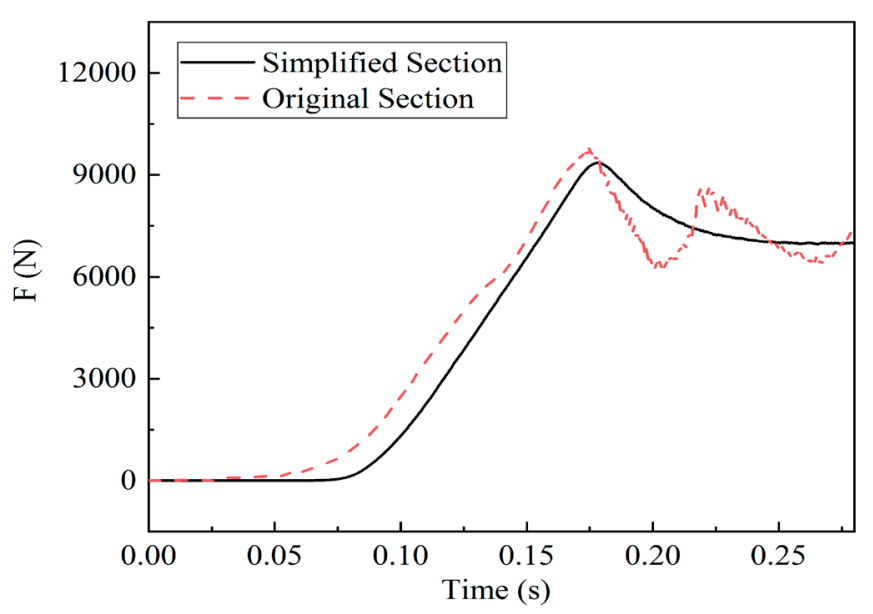

Fig. 20. The comparison of vertical impact forces on the bow-fared area $(y>380$ $\mathrm{mm}$ ) between two sections

Fig. 18 shows the impact pressure of the simplified section obtained by using different flow models. The impact velocity is constant at $4 \mathrm{~m} / \mathrm{s}$. It can be seen that the numerical results of different flow models are in good agreement, which is consistent with the previous study on the water entry of the wedge [35]. Therefore, the selection of flow model has little influence on the numerical results when there is no flow separation and secondary impact phenomena during water entry.

Fig. 19 shows the comparison of impact pressure at typical locations. For the $\mathrm{P} 2$ position, which is obviously affected by the secondary impact, the peak value of impact pressure is obtained by using the original section, which is larger than that of the simplified section. For the locations P1, P3, P4 and $\mathrm{P} 5$, the impact pressure obtained by using the original section is less than that of the simplified section. This means that the impact pressure obtained by using the simplified section is relatively conservative for most locations on the section.

Fig. 20 shows the comparison of vertical impact forces on the bow-fared area $(y>380 \mathrm{~mm})$ between two sections. The equation of motion of a water-entered object is written as $\mathrm{Mg}+\mathrm{Fb}+\mathrm{Fd}+\mathrm{Fc}+\mathrm{F}=\mathrm{m} \xi$. The forces to be considered are the inertia force $(\mathrm{Mg})$, buoyancy force $(\mathrm{Fb})$, drag force $(\mathrm{Fd})$, capillary force $(\mathrm{Fc})$, and the impact force $(\mathrm{F})$, which is the force that is applied by the fluid on the object. It can be seen that the variation trend of impact forces of two sections are very close. At the initial moment of time, the original section receives a greater impact force than the simplified section, due to the presence of a flat horizontal section on the cross section of the bulbous bow. For the zone below P1, the flat horizontal section of the bulb increases the initial impact force. This happens at the expense of large initial significance of added masses of water. The simplified section initially interacts with small added masses. The deviation of peak impact force between the two sections is approximately $4.53 \%$.

\section{CONCLUSIONS}

Bulbous bow is a typical structure for a ship bow. However, there is little research on the water impact test of ship-like sections with bulbous bow structures. For the ship-like sections in the previous tests carried out by Aarsnes [17] and MOERI [23], the size of the bulbous bow is small and no cavities (or only small cavities) appear during water entry. In this paper, experimental and numerical studies on the hydrodynamics during the water entry of a ship-like section were carried out.

The free-fall drop test is carried out in the test rig equipped with guide rails. By changing the drop height, the impact pressure on the model surface with different initial impact velocities is measured. The profile of the model is unchanged along the length direction, and two thin plates are installed at both ends of the model. By comparing the test data of the two same test conditions, the experimental results show good repeatability. By comparing impact pressures at the locations which have the same height but different longitudinal positions, it is found that the impact pressure in the middle part of the model varies very little along the length direction, which indicates that the flow field in the middle part of the model is similar to the water entry of the twodimensional section.

The water entry of the ship-like section is numerically studied by using the commercial Computational Fluid Dynamics (CFD) solver StarCCM+. The motion of the grid around the ship section is realised by using the overset mesh method. Numerical results show good convergence of time step and mesh size. Four different flow models are used in numerical analysis. It is found that the Laminar model cannot reasonably predict the flow separation and gas capture phenomena near the bulbous bow. By comparing the numerical results with the experimental results, it is found that the K-Epsilon turbulence model shows better agreement with the experimental results than other flow models. The simulation results of $\mathrm{P} 1, \mathrm{P} 3, \mathrm{P} 4$ and $\mathrm{P} 5$ are in good agreement with the experimental results. The simulation result of $\mathrm{P} 2$ is not good because of the secondary impact of the separated liquid and the air cushion effect.

Referring to the previous studies on the simplified treatment of the original bulbous bow section, a simplified section without a bulbous bow is introduced to discuss the influence of bulbous bow on the impact loads. For the simplified section without a bulbous bow, the numerical results of different flow models are very close, which is consistent with the previous study on the water entry of the wedge. By comparing the impact pressure of the two sections, it is found that the bulbous bow reduces the impact pressure at most positions on the ship-like section, but increases the local impact pressure near the bulbous bow (P2 location) due to the secondary impact of the separated fluid. By comparing the impact force of the two sections, it is found that the bulbous bow has little effect on the impact force acting on the bow-flared area. 
In the present study, pressures for points located on the bulb bow have not been obtained due to the installation limitation of sensors. Further research is needed for the water entry experiment about the bow section with different bulb shape and installation of sensors.

\section{ACKNOWLEDGEMENTS:}

The authors are grateful to the State Key Laboratory of Ocean Engineering (Shanghai Jiao Tong University) (1904), the Fundamental Research Funds for the Central Universities (3132018201) and the Natural Science Foundation of Liaoning Province (2020-MS-125).

\section{REFERENCES}

1. S.E. Hirdaris, W. Bai, D. Dessi, et al., "Loads for use in the design of ships and offshore structures", Ocean Engineering. 2014. Vol. 78, 131-174, doi: 10.1016/j.oceaneng.2013.09.012.

2. J. JIAO, H. REN, C. CHEN. Model Testing for Ship Hydroelasticity: A Review and Future Trends[J]. Journal of Shanghai Jiao Tong University (Science), 2017, 22(6): 641-650.

3. J. Jiao, H. Yu, C. Chen, et al., “Time-domain numerical and segmented model experimental study on ship hydroelastic responses and whipping loads in harsh irregular seaways", Ocean Engineering. 2019. Vol. 185, 59-81, doi: 10.1016/j. oceaneng.2019.05.039.

4. S.Y. Sun, H.L. Chen, and G. Xu, "Water Entry of A Wedge Into Waves in Three Degrees Offreedom”, Polish Maritime Research. 2019. Vol. 26(1), 117-124, doi:10.2478/ pomr-2019-0013.

5. T. Von Karman, "The impact on seaplane floats during landing”, NACA Technical note no.321,1929.

6. H.Wagner, “Uber Stoss- und Gleitvorgange an der Oberflache von Flussigkeiten. “ZAMM, 12, 193-215,1932.

7. Z. Dobrovol'skaya "On some problems of similarity flow of fluid with a free surface", Journal of Fluid Mechanics. 1969. Vol. 36, 805-829, doi: 10.1017/S0022112069001996.

8. R. Zhao and O. Faltinsen, "Water entry of two-dimensional bodies”, Journal of Fluid Mechanics. 1993. Vol. 246, 593 612, doi: 10.1017/S002211209300028X.

9. J. Wang and O.M. Faltinsen, "Improved numerical solution of Dobrovol'skaya's boundary integral equations on similarity flow for uniform symmetrical entry of wedges", Applied Ocean Research. 2017. Vol. 66, 23-31, doi: 10.1016/j. apor.2017.05.006.
10. A. Kamath, H. Bihs, and O.A. Arntsen, "Study of Water Impact and Entry of a Free Falling Wedge Using Computational Fluid Dynamics Simulations", Journal of Offshore Mechanics and Arctic Engineering-Transactions of the Asme. 2017. Vol. 139(3), doi: 10.1115/1.4035384.

11. E.M. Yettou, A. Desrochers, and Y. Champoux, "Experimental study on the water impact of a symmetrical wedge”, Fluid Dynamics Research. 2006. Vol. 38(1), 47-66, doi: 10.1016/j.fluiddyn.2005.09.003.

12. M. Jalalisendi, S. Zhao, and M. Porfiri, "Shallow water entry: modeling and experiments", Journal of Engineering Mathematics. 2017. Vol. 104(1), 131-156, doi: 10.1007/ s10665-016-9877-3.

13. R. Panciroli, A. Shams, and M. Porfiri, "Experiments on the water entry of curved wedges: High speed imaging and particle image velocimetry", Ocean Engineering. 2015. Vol. 94, 213-222, doi: 10.1016/j.oceaneng.2014.12.004.

14. P. Yu, H. Li, and M.C. Ong, "Numerical study on the water entry of curved wedges", Ships and Offshore Structures. 2018. Vol. 13(8), 885-898, doi: 10.1080/17445302.2018.1471776.

15. M. Barjasteh, H. Zeraatgar, and M.J. Javaherian, “An experimental study on water entry of asymmetric wedges", Applied Ocean Research. 2016. Vol. 58, 292-304, doi: 10.1016/j.apor.2016.04.013.

16. Y. Chen, T. Khabakhpasheva, K.J. Maki, et al., "Wedge impact with the influence of ice", Applied Ocean Research. 2019. Vol. 89, 12-22, doi: 10.1016/j.apor.2019.05.001.

17. J. Aarsnes. "Drop test with ship sections - effect of roll angle”, Report 603834.00.01. Norwegian Marine Technology Research Institute, Trondheim, Norway, 1996.

18. R.Zhao, O.M. Faltinsen and J. Aarsnes. "Water entry of arbitrary two-dimensional sections with and without flow separation", Proceedings of the 21st symposium on naval hydrodynamics, Trondheim, Norway, National Academy Press, Washington, DC, USA, 1996.

19. H. Sun and O.M. Faltinsen, "Water entry of a bow-flare ship section with roll angle", Journal of Marine Science and Technology. 2009. Vol. 14(1), 69-79, doi: 10.1007/ s00773-008-0026-1.

20. X. Zhu, O.M. Faltinsen, C. Hu ."Water entry loads on heeled ship sections". In: Proc. 16th Int Conf Hydrodyn Ship Design, Gdansk, Poland, 2005.

21. S. Wang and C. Guedes Soares, "Slam induced loads on bowflared sections with various roll angles", Ocean Engineering. 2013. Vol. 67, 45-57, doi: 10.1016/j.oceaneng.2013.04.009. 
22. H. Xie, H. Ren, H. Li, et al., "Numerical prediction of slamming on bow-flared section considering geometrical and kinematic asymmetry", Ocean Engineering. 2018. Vol. 158, 311-330, doi: 10.1016/j.oceaneng.2018.04.033.

23. MOERI. Wave Induced Loads on Ships. Technical Report No BSPIS7230-10306-6. Maritime Ocean Engineering Research Institute, Daejeon, Korea ,2013.

24. Y. Kim, K.-K. Yang, J.-H. Kim, et al., "Study of Water-entry Impact of Wedge and Ship-like Section Using Potential Theories and CFD", International Journal of Offshore and Polar Engineering. 2017. Vol. 27(2), 168-176, doi: 10.17736/ ijope.2017.jc670.

25. L. Yang, H. Yang, S. Yan, et al., "Numerical Investigation of Water-Entry Problems Using IBM Method", International Journal of Offshore and Polar Engineering. 2017. Vol. 27(2), 152-159, doi: 10.17736/ijope.2017.jc687.

26. J. Park, J.H. Choi, H.-h. Lee, et al., "Experimental study on the effects of stern bulb arrangement on the slamming load", International Journal of Naval Architecture and Ocean Engineering. 2020. Vol. 12, 518-530, doi: 10.1016/j. ijnaoe.2020.03.006.

27. B. Guzel and F.C. Korkmaz, "Reducing Water Entry Impact Loads on Marine Structures by Surface Modification", Brodogradnja. 2020. Vol. 71(1), 1-18, doi: 10.21278/ brod71101.

28. H. Luo, H. Wang, and C. Guedes Soares, "Numerical and experimental study of hydrodynamic impact and elastic response of one free-drop wedge with stiffened panels", Ocean Engineering. 2012. Vol. 40, 1-14, doi: 10.1016/j. oceaneng.2011.11.004.

29. D. Van Nuffel, K.S. Vepa, I. De Baere, et al., "Study on the Parameters Influencing the Accuracy and Reproducibility of Dynamic Pressure Measurements at the Surface of a Rigid Body During Water Impact”, Experimental Mechanics. 2013. Vol. 53(2), 131-144, doi: 10.1007/s11340-012-9619-z.

30. B. Zhang, " Research on Ship Hull Optimisation of HighSpeed Ship Based on Viscous Flow/Potential Flow Theory “, Polish Maritime Research. 2020. Vol. 27(1), 18-28, doi: 10.2478/pomr-2020-0002.

31. L.-F. Hu, H. Qi, Y. Li, et al., “The CFD Method-Based Research on Damaged Ship's Flooding Process in TimeDomain”, Polish Marit. Res., vol. 26, no. 1, 2019, doi: 10.2478/pomr-2019-0009.

32. H. Nguyen Thi Ngoc, B. Vu Ngoc, T. Tran Ngoc, et al.," Numerical Investigating the Effect of Water Depth on Ship Resistance Using RANS CFD Method", Polish Marit. Res., vol. 26, no. 3, 2019, doi: 10.2478/pomr-2019-0046.
33. Q. Wang, B. Zhang, P. Yu, et al., "Numerical Investigation on the Water Entry of Several Different Bow-Flared Sections", Applied Sciences-Basel. 2020. Vol. 10(22), doi: 10.3390/app10227952.

34. S. Johannessen, "Use of CFD to Study Hydrodynamic Loads on Free-Fall Lifeboats in the Impact Phase: A Verification and Validation Study," M.Sc. Thesis, Norwegian University of Science and Technology, 2012.

35. R.N. Bilandi, S. Jamei, F. Roshan, et al., "Numerical simulation of vertical water impact of asymmetric wedges by using a finite volume method combined with a volumeof-fluid technique”, Ocean Engineering. 2018. Vol. 160, 119-131, doi: 10.1016/j.oceaneng.2018.04.043.

36. A. Bereznitski, Slamming: The role of hydroelasticity [J]. Int Shipbuild Progr,2001,48(4):333-351.

37. S.-L. Chuang, "Experiments on Slamming of WedgeShaped Bodies", Journal of Ship Research. 1967. Vol. 11, 190-198, doi: 10.5957/jsr.1967.11.3.190.

38. O.A. Hermundstad and T. Moan, "Numerical and experimental analysis of bow flare slamming on a Ro-Ro vessel in regular oblique waves", Journal of Marine Science and Technology. 2005. Vol. 10(3), 105-122, doi: 10.1007/ s00773-005-0192-3.

39. J.-H. Kim, Y. Kim, R.-H. Yuck, et al., "Comparison of slamming and whipping loads by fully coupled hydroelastic analysis and experimental measurement", Journal of Fluids and Structures. 2015. Vol. 52, 145-165, doi: 10.1016/j. jfluidstructs.2014.10.011. 


\section{CONTACT WITH THE AUTHORS}

\section{Qiang Wang}

e-mail:wangqiang5120@dlmu.edu.cn

Dalian Maritime University,

No.1 Ganjingzi District, 0086116026 Dalian,

\section{China}

\section{Pengyao Yu}

e-mail:yupengyao@dlmu.edu.cn

Dalian Maritime University,

No.1 Ganjingzi District, 0086116026 Dalian,

\section{China}

\section{Boran Zhang}

e-mail:brzhang@ccs.org.cn

Dalian Maritime University,

No.1 Ganjingzi District, 0086116026 Dalian,

\section{China}

\section{Guangzhao Li}

e-mail: liguangzhao@dlmu.edu.cn

Dalian Maritime University,

No.1 Ganjingzi District, 0086116026 Dalian,

China 